\title{
Segundo Coloquio Internacional: «Conservadores y contrarrevolucionarios en el espacio euroamericano (siglos XIX-XX). Transferencias, circulaciones, influencias»
}

México, 18 y 19 de febrero de 2013

\section{Georges Lomné}

\section{(2) OpenEdition Journals \\ Edición electrónica \\ URL: http://journals.openedition.org/bifea/953 \\ DOI: 10.4000/bifea.953 \\ ISSN: 2076-5827 \\ Editor \\ Institut Français d'Études Andines}

Edición impresa

Fecha de publicación: 1 abril 2013

Paginación: 135-140

ISSN: 0303-7495

\section{Referencia electrónica}

Georges Lomné, « Segundo Coloquio Internacional: «Conservadores y contrarrevolucionarios en el espacio euroamericano (siglos XIX-XX). Transferencias, circulaciones, influencias» », Bulletin de I'Institut français d'études andines [En línea], 42 (1) | 2013, Publicado el 01 octubre 2013, consultado el 06 noviembre 2020. URL : http://journals.openedition.org/bifea/953 ; DOI : https://doi.org/10.4000/ bifea.953

Les contenus du Bulletin de l'Institut français d'études andines sont mis à disposition selon les termes de la licence Creative Commons Attribution - Pas d'Utilisation Commerciale - Pas de Modification 4.0 International. 


\title{
Eventos
}

\section{SEGUNDO COLOQUIO INTERNACIONAL: "CONSERVADORES Y CONTRARREVOLUCIONARIOS EN EL ESPACIO EUROAMERICANO (SIGLOS XIX-XX). TRANSFERENCIAS, CIRCULACIONES, INFLUENCIAS»}

\author{
México, 18 y 19 de febrero de 2013
}

Este coloquio tuvo lugar en El Colegio de México, los días lunes 18 y martes 19 de febrero. Fue convocado y coordinado por Jordi Canal (EHESS), en nombre de las instituciones que lo coorganizaron: la Casa de Velázquez, representada en esta ocasión por su director de estudios para las épocas moderna y contemporánea, Stéphane Michonneau; el CEMCA, representado por su directora Delphine Mercier; la Universidad de Hamburgo, y el IFEA, representado por su director, Gérard Borras. El evento logró reunir a 20 conferencistas y moderadores de 6 países distintos y contó con el apoyo del Centro Nacional de la Investigación Científica (CNRS, Francia), del Colegio Franco-Mexicano en Ciencias Sociales y del Instituto Universitario de Francia (IUF).

El 18 de febrero, en la Sala Alfonso Reyes, Jordi Canal delineó las pautas científicas del proyecto. De entrada, recordó los pasos a seguir: este coloquio constituiría el segundo después de la reunión preparatoria que tuvo lugar en Lima el año anterior (Lomné, 2012) previamente a otros futuros, bajo forma de dos coloquios en Madrid (febrero de 2014) y en Hamburgo. Recalcó luego la utilidad de estudiar un «ángulo muerto» de la historiografía, y bajo un enfoque verdaderamente interdisciplinario. Prosiguió enfatizando la necesidad de contemplar para ello un espacio euroamericano que permitiera analizar las circulaciones entre ambos continentes, sin sobrevalorar las que tuvieron lugar a partir de Europa. Jordi Canal precisó finalmente que este proyecto constituiría más un punto de partida que un punto de llegada. Si el coloquio de Lima permitió delinear al proyecto, el de México sería consagrado más específicamente al siglo XIX y el de Madrid al siglo XX.

A continuación, Annick Lempérière (Universidad de París-I, Sorbona, e IUF) dio una conferencia inaugural sobre el tema: «Euro-América, un espacio-tiempo transnacional». Destacó al respecto el carácter pionero del postulado de François- 
Xavier Guerra de un espacio euroamericano de corte hispano (Guerra, 2012), contrastándolo con el de la Atlantic History, centrado sobre el Atlántico norte y sus dependencias caribeñas (Vidal, 2012). Enfatizó luego la necesidad de tomar en cuenta la experiencia que constituía una circulación: ¿acaso cada una de ellas no transformaba los propios entornos sociales que la manejaban? Subrayó también la necesidad de introducir a los Estados Unidos en la reflexión, ya que eran en el siglo XIX, para muchos hispanoamericanos, el modelo sin parangón de la libertad. Por lo tanto, la perspectiva euro-americana evitaría el escollo de la historia fragmentada y permitiría realzar unas categorías de análisis poco usadas por los historiadores de las independencias: la de «emigrados», o la de «legitimistas», para caracterizar a los realistas peninsulares o criollos que lucharon en América contra los patriotas.

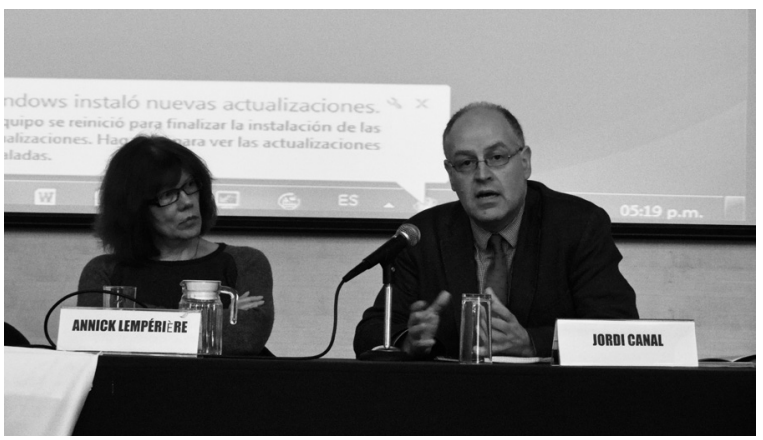

En la segunda parte de su conferencia, Annick Lempérière destacó el carácter borroso de la noción de «conservador». $\mathrm{Si}$ resulta fácil identificar al «contrarrevolucionario», no es el caso del «conservador». De manera teleológica, la historiografía hispanoamericana ha tildado de conservadores a criollos que los europeos del Congreso de Viena ihasta fustigaban por su liberalismo! Conviene recalcar también lo complejo de ciertas trayectorias personales como la de Lucás Alamán en México, que se hizo conservador, o de la de Bartolomé Herrera en Lima, un acérrimo conservador que leía sin embargo a Victor Cousin y a los Doctrinarios. En esta misma vena, resulta obvio que algunos autores europeos fueron leídos a la vez por Liberales y Conservadores, como es el caso de Lamennais en la Nueva Granada. En resumidas cuentas, existió un verdadero pluralismo del conservadurismo en la primera mitad del siglo XIX. Una referencia, como el Ultramontanismo, constituyó a pesar de todo un nítido marcador. En la segunda mitad del siglo XIX, el asociacionismo político sustituyó las migraciones políticas como elemento clave en la fabricación de las ideologías. Empero, permaneció intacta la dimensión euro-americana de los lazos que establecieron estas sociétés savantes con sus homólogas europeas. En la discusión que siguió, José María Portillo y Annick Lempérière realzaron la importancia del «abordaje político» de la temática aunque la actitud frente a la Religión, un horizonte mucho más amplio que la estricta política, era esencial en la definición del conservadurismo. Jordi Canal recalcó entonces la necesidad de no apartar al mundo ibérico de una reflexión de conjunto sobre Occidente, tal como pudo hacerlo Niall Ferguson, en un reciente y polémico libro (Ferguson, 2011). La discusión tornó luego acerca del buen uso de los conceptos. Jordi Canal explicó por qué había descartado la voz de «derecha», demasiado ambigua, y por qué la voz de «reaccionario» le parecía peyorativa al no traducir el carácter moderno de los conservadores. Todos acordaron finalmente la necesidad de abandonar la caduca noción de «influencia» a favor de la categoría de «transferencia cultural». 
En la tarde del 18 de febrero, una primera mesa de trabajo moderada por Ricardo Pérez Monfort (CIESAS, México), permitió escuchar a José C. Moya (Barnard College, Columbia University) sobre «Derechas y exilios en el mundo atlántico, 17891989: En busca de pautas explicativas»; a Manuel Lucena Giraldo (CSIC, España) sobre: «ílejos o cerca del Humboldtianismo? Visiones de la obra de Humboldt en la Hispanoamérica del Siglo XIX» y a Erika Pani Bano (Colegio de México) sobre «Como México no hay dos: el conservadurismo mexicano y sus referentes europeos». José C. Moya enseñó cómo, en Hispanoamérica, la «yanquifobia» había sustituido paulatinamente la hispanofobia. Manuel Lucena trató luego de entender la mitologización de Humboldt por los nacionalistas del siglo XIX, haciendo de su figura el segundo descubridor de América. No es menor paradoja de parte de quien fue considerado en su tiempo como un portavoz autorizado de la ciencia borbónica. El énfasis que pondría en el carácter sublime de la naturaleza americana y sus potencialidades económicas a futuro, hacen quizás de él un conservador por antonomasia. Erika Pani, al centrarse sobre el tema de los referentes a Europa en el discurso de los católicos mexicanos de la época de la Reforma destacó el carácter transnacional de su visión de la patria y de la Iglesia.

Una segunda mesa, moderada por Georges Lomné (Universidad de ParísEste, Marne-la-Vallée) brindó cuatro intervenciones: la de José María Portillo (Universidad del País Vasco, UPV) sobre «El pensamiento conservador ante el momento de la emancipación»; la de Alfredo Ávila (Instituto de Investigaciones Históricas, IIH-UNAM, México) sobre «De serviles a conservadores, 18201824»; la de Pedro Rújula (Universidad de Zaragoza, España) sobre «Realismo transoceánico: la aventura peninsular de Antonio Joaquín Pérez, 1810-1816» y la de Tomás Pérez Vejo (Escuela Nacional de Antropología e Historia, ENAH, México) sobre «Españoles en la Guerra de Reforma de México: el caso del general José María Cobos». José María Portillo cuestionó la validez del sintagma «revolución de independencia», el vínculo entre libertad e independencia y el significado de la voz emancipación en clave jurídica. Destacó en particular el uso que hizo de estas voces el canónigo mexicano Manuel de la Bárcena y Arce, ardiente defensor de un ordo universalis cristiano y monárquico. Más atento a la actuación del obispo de Sonora, Fray Bernardo del Espíritu Santo Martínez y Ocejo, Alfredo Ávila se interrogó sobre la posible genealogía en México entre serviles, escoceses y conservadores. Ávila opuso la visión orgánica que vincula esta a la supervivencia y defensa del orden corporativo, a otro modelo interpretativo que postula un conservatismo desligado de raíces coloniales. A continuación, Pedro Rújula se interesó en el diputado de Puebla en las Cortes de Cádiz, el canónigo Antonio Joaquín Pérez Martínez y Robles. Este personaje encarnó mejor que cualquier otro la circulación euro-americana del realismo: enemigo de Agustín Argüelles y de la carta constitucional, fue el único americano que llegó a presidir dos veces las Cortes. Su papel fue considerable en la firma del Manifiesto de los Persas y en el restablecimiento de la monarquía absoluta de Fernando VII. De manera simétrica, la ponencia de Tomás Pérez Vejo detalló la participación del «gachupín Cobos», en el bando conservador, durante la guerra de Reforma en México. Este caso particular permitió enseñar la importancia del debate sobre la identidad nacional 
en la diferenciación entre conservadores y liberales. De menor importancia para los primeros, era esencial para los segundos.

En la mañana del martes 19 de febrero tuvo lugar una tercera mesa, moderada por Jordi Canal (EHESS). Expusieron Camille Foulard (Cemca) sobre «La experiencia contrariada de las Hermanas de la Caridad en México (1844-1875): una aproximación política»; Marta Eugenia Ugarte (Instituto de Investigaciones Sociales, IIS-UNAM) sobre «Participación de la Iglesia católica en la formación del Partido Católico Nacional. Una distinción conceptual y práctica, 1904-1914»; Elisa Cárdenas Ayala (Universidad de Guadalajara, México) sobre «Acción social y democracia cristiana en el cambio de siglo ¿conceptos para la contrarrevolución?» y Carmine Pinto (Università degli studi di Salerno) sobre «Héroes y aventureros. Los voluntarios legitimistas europeos en el fin del Reinado de Napoli (1860-1866)». La ponencia de Camille Foulard detalló primero el proceso de asentamiento de las hermanas en México en reemplazo de sus homólogas españolas. Se interesó luego en su divorcio gradual con el régimen imperial y en su condena y expulsión por el propio gobierno mexicano, en 1875. En suma, la ponencia brindó un interesante ejemplo de participación europea en la renovación cristiana deseada por el papa Pío IX. La ponencia siguiente, a cargo de María Eugenia Ugarte, cuestionó de entrada la opinión de Justo Sierra, en 1878, según la cual México había carecido de un verdadero partido conservador al no tener sino meros reaccionarios. Si la fundación del Partido Católico Nacional (PCN) vendría a colmar tal anhelo en 1911, fueron significativos a partir de 1902 los intentos de la Santa Sede de mandar a México a un número significativo de jóvenes curas y obispos formados en Roma. Elisa Cárdenas brindó luego un lúcido y brillante panorama del nacimiento de la democracia cristiana en Roma y en México. Contrastó primero el pontificado de Pío IX (1846-1878), obsesionado por la acción del demonio en el siglo, con el pontificado de León XIII (1878-1903), de corte humanista y deseoso de incentivar la acción social de la Iglesia. En 1899, nacería así el concepto de la democracia cristiana. El Papa León X (1903-1914), conocido por su anti-modernismo, trataría de volver a definirla, vinculándola a lo social y poniéndola bajo el control del clero. Los «Operarios Guadalupanos» surgieron en este contexto, favoreciendo luego la formación del PCN. Unos movimientos que no debemos tildar de «contrarrevolucionarios» ya que abogaban a favor de formas políticas modernas. Al abordar otro contexto, la ponencia de Carmine Pinto quiso clarificar lo que fue el Brigantaggio en el reino de Nápoles, entre 1799 y 1914, y dar nuevas luces sobre la importancia del exilio de los contrarrevolucionarios italianos y su participación en las guerras carlistas.

En la tarde, tuvo lugar la cuarta y última mesa del coloquio, moderada por Stéphane Michonneau (Casa de Velázquez). Hablaron sucesivamente: Robert Curley (Universidad de Guadalajara) sobre «El catolicismo social y la modernidad religiosa: México y España a principios del siglo XX»; Carlos Espinosa (Flacso, Ecuador), sobre: «El "terrorismo" conservador en Ecuador (1875-1900): la radicalización de los conservadores después del asesinato de García Moreno»; Rafael Rojas (CIDE) sobre «Los últimos porfiristas: entre el reformismo y la contrarrevolución, 
1908-1915» y Elisa Speckman (IIH-UNAM) sobre «El determinismo orgánico y el cuestionamiento de la igualdad (México, 1884-1929)». Robert Curley trató de demostrar que el catolicismo social debía historiarse fuera del contexto nacional: el «momento de la acción social» (1870-1930) merecería un campo de estudio euroamericano que permitiera establecer contrastes, por ejemplo entre España y México. Advirtió también Curley en contra de la «trampa analítica» que consistiría en establecer una filiación entre el catolicismo social y la contrarrevolución. Más fructífero resultaría trabajar a contra-corriente y buscar a conservadores entre los revolucionarios, y a revolucionarios entre los conservadores. En otro contexto, el Ecuador posgarciano, Carlos Espinosa analizó la reformulación del conservadurismo bajo la vindicta de liberales que lo tildaron de «terrorista». El año de 1877 brindó el paroxismo de una contienda que se situó en varios escenarios: en marzo, el asesinato del arzobispo José Ignacio Checa y Barba; en mayo, unos grupos de «rezadores» que atacaron los cuarteles de Quito después del cierre de las iglesias por Veintimilla; en noviembre, un golpe en Ibarra y una guerra civil consecuente al grito de «!Viva el Sagrado Corazón de Jesús!». En los años 1880, el enfrentamiento se situaría a través de la prensa de opinión y los conservadores se dividirían en dos bandos, radical y moderado. La circulación de ideas sería entonces intensa, muy en particular desde Roma y Francia. Volviendo al caso mexicano, Rafael Rojas enseñó luego cómo la contrarrevolución que sufrió Francisco Madero fue incentivada, a manera de paradoja, por un grupo de reformistas de la época de Porfirio Díaz. Estos apoyaron a Victoriano Huerta en 1913 y conformarían su gabinete, tratando de encarrilar la revolución por otra vía. Elisa Speckman habló a continuación del auge de la topología criminal en México a partir de la antropometría desarrollada en Europa por Cesare Lombroso (1835-1909) y Alphonse Berthillon (1853-1914). La idea de «atavismo» vinculada a los «tipos criminales» tendió en México a facilitar la condena de individuos de marcados rasgos indígenas. El eugenismo bebería luego de esta fuente.

Jordi Canal cerró los debates del coloquio reafirmando la necesidad de escribir una historia transnacional de las circulaciones y transferencias políticas conservadoras, que tuviera en cuenta una serie de «experiencias». Llevarla a bien supondría la clarificación de las categorías de «conservador», «reaccionario»e, incluso, «terrorista». También haría falta considerar el papel imperante de la Iglesia. ¿Acaso este coloquio no enseñó al espacio euroamericano como una «comunidad religiosa», en palabras de Erika Pani? Por lo tanto, muchas líneas de trabajo quedaron abiertas: el vínculo entre Catolicismo y Modernidad; la importancia de los referentes intelectuales europeos; la relación del conservadurismo al derecho; las estrategias de grupo e individuales; la dinámica del exilio y la circulación de libros y recursos financieros. En resumidas cuentas, este coloquio contribuyó a delinear un nuevo «territorio de estudio». 


\section{Referencias citadas}

FERGUSON, N., 2011 - Civilization. The West and the Rest, 432 pp.; New York: The Penguin Press.

GUERRA, F.-X., 2012 - Figuras de la Modernidad. Hispanoamérica. Siglos XIX-XX, 432 pp.; Bogotá: Universidad Externado de Colombia, Taurus. Colección estudios en historia. Annick Lempérière y Georges Lomné, eds.

LOMNÉ, G., 2012 - Conservadores y contrarrevolucionaros en el espacio euroamericano (siglos XIX-XX). Transferencias, circulaciones, influencias. Lima, 11 y 12 de junio de 2012. Bulletin de l'Institut Français d'Études Andines, 41 (2): 307-311.

VIDAL, C., 2012 - Pour une histoire globale du monde atlantique ou des histoires connectées dans et au-delà du monde atlantique? Annales HSS, abril-junio, $\mathbf{n} .^{\circ} \mathbf{2}$ : 391-413; París: Armand Colin. 